Portland State University

PDXScholar

3-1-2018

\title{
Actualizing Teacher Pedagogical Aims Through One to One Student to Chromebook Integration: a Case Study
}

Alaina Loescher

Portland State University

Follow this and additional works at: https://pdxscholar.library.pdx.edu/honorstheses

Let us know how access to this document benefits you.

\section{Recommended Citation}

Loescher, Alaina, "Actualizing Teacher Pedagogical Aims Through One to One Student to Chromebook Integration: a Case Study" (2018). University Honors Theses. Paper 501.

https://doi.org/10.15760/honors.505

This Thesis is brought to you for free and open access. It has been accepted for inclusion in University Honors Theses by an authorized administrator of PDXScholar. Please contact us if we can make this document more accessible: pdxscholar@pdx.edu. 
Running head: TEACHER PEDAGOGICAL AIMS THROUGH 1:1 CHROMEBOOKS

Actualizing Teacher Pedagogical Aims Through One to One Student to Chromebook Integration: A Case Study

\author{
by \\ Alaina Loescher \\ An undergraduate honors thesis submitted in partial fulfillment of the \\ requirements for the degree of \\ Bachelor of Arts \\ in \\ University Honors \\ and \\ Child and Family Studies \\ Thesis Adviser \\ Dr. Erin Elizabeth Flynn
}

Winter 2018 


\begin{abstract}
Current research in the field of educational technology operates under the assumption that one to one student to technology use in classroom has the capacity to increase student achievement while placing responsibility on teachers to actualize this aim. However, qualitative research is needed that illustrates real teachers' integration of technology in their classrooms. Thus, this research employs participant-observer, case study methodology to answer the question: How is one teacher utilizing Chromebooks at a 1:1 student to device ratio in accordance with her own personal pedagogical beliefs? This research found that the participant teacher utilized Chromebooks, and specifically the sites Khan Academy, DreamBox, Bookshelf, Google Classroom and Seesaw, in order to actualize her pedagogical belief of differentiation. This research ultimately makes the case that educational technology research should be descriptive of the way that current teachers are utilizing technology in accordance with pedagogical beliefs before it attempts to be evaluative of teacher success with technology integration.
\end{abstract}

Key Words: One to one initiatives, Chromebook, Pedagogical beliefs, Differentiation, Khan Academy, DreamBox, Bookshelf, Google Classroom, Seesaw 


\section{TABLE OF CONTENTS}

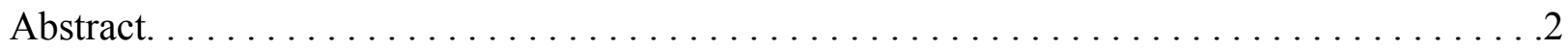

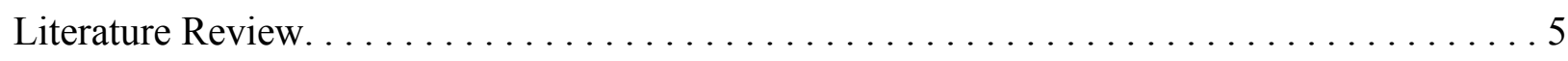

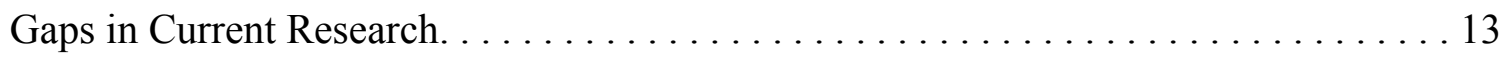

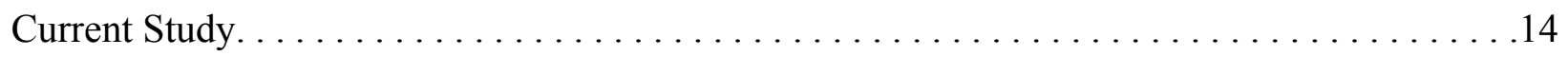

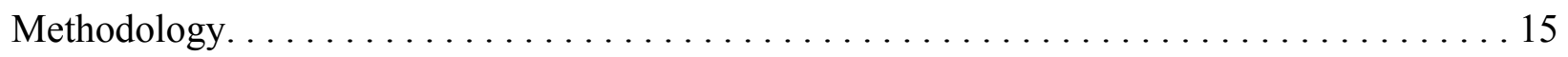

Sample. ................................. 15

Role of the Researcher. . . . . . . . . . . . . . . . . . . . .

Data Collection. .............................. 17

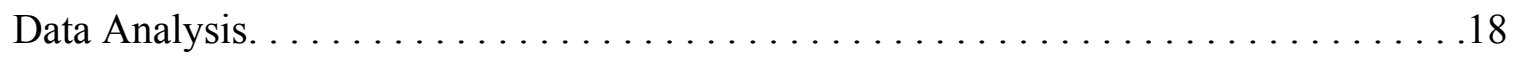

Results. .................................. 19

Pedagogical Beliefs of the Participant Teacher. . . . . . . . . . . . . . . . 19

Functionality of Chromebooks as Classroom Technology. . . . . . . . . . 21

Khan Academy and DreamBox as Math Tool. .....................

Bookshelf as a Reading Tool. . . . . . . . . . . . . . . . . . . 27

Google Classroom as a Writing Tool. . . . . . . . . . . . . . . . . 30

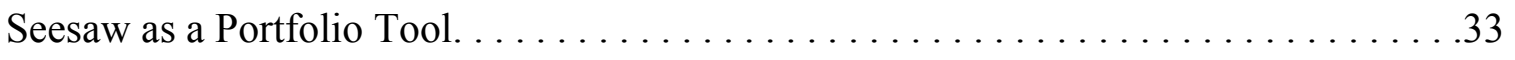

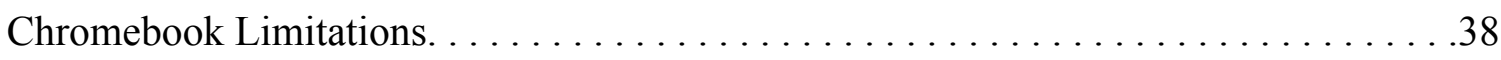

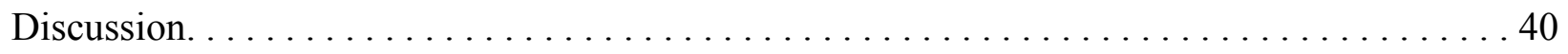

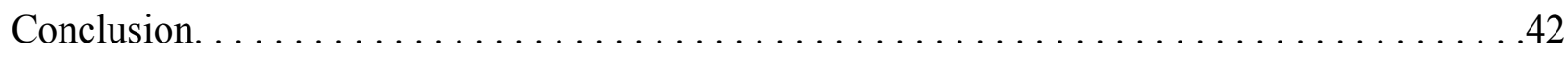

Future Research. .................................43 


\section{TABLE OF FIGURES}

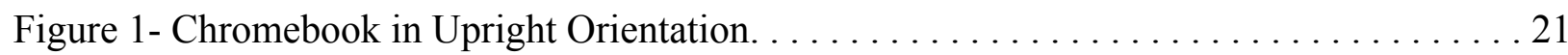

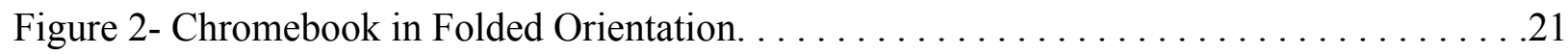

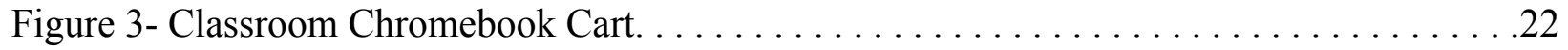

Figure $4-$ Khan Academy Functionality. . . . . . . . . . . . . . . 23

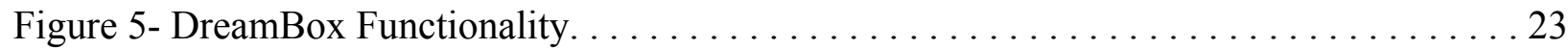

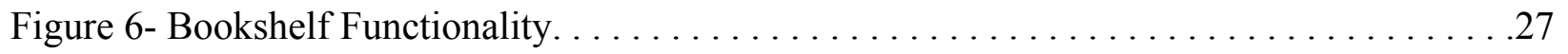

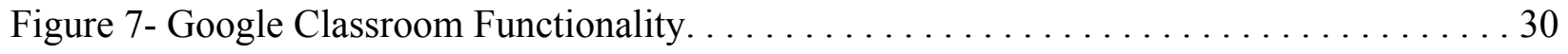

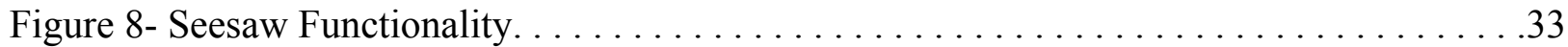


"This is the age. These kids grew up with computers and they know how to use them as tools. It isn't novelty enrichment; we are teaching basic curriculum on Chromebooks. It's not like it was when I was first in teaching. It isn't an extra thing. We are using computers to teach reading, to teach writing, to teach math, to teach research. I'm not saying it's a replacement for the pen, for paper, but it is definitely an important tool we are using to teach."

-Mrs. Welsh

\section{Literature Review}

In the field of educational technology, there are two overarching discourses. The first of these discourses represents the pre-No Child Left Behind (NCLB) Act. This discourse questions whether or not technology implementation in classrooms could be superior to traditional teaching practices. Kent and McNergney's (1999) book titled Will Technology Really Change Education? represents the pre-NCLB discourse. This book argues that the ability for students to have on-command access to the abundant knowledge available on the World Wide Web leads to a distinctive change in education. This change catalyzes teachers to formulate more constructivist pedagogies, meaning creation of a student-centered classroom dynamic in which learning is achieved through hands-on experimentation.

Kent and McNergney (1999) also argue that technology is only as effective as the teacher's ability and willingness to integrate the technology into his/her teaching practice. Larry Cuban, in his 2001 book Oversold and Underused: Computers in the Classroom, argues that technology is typically implemented infrequently and arbitrarily in classrooms. As a result, the pre-NCLB discourse revolves around the belief that teaching would not necessarily improve as a result of technology implementation. The pre-NCLB discourse ultimately asserts that teaching tactics need to be revamped, but that technology in classrooms would only be beneficial if it improved teaching practices.

With the NCLB act of 2001 came a focus on improving student achievement with technology at the forefront of this aim. Fears regarding technology implementation in classrooms 
were swept under the rug as technology became synonymous with increasing student achievement in American public schools. With this push, schools began increasing funding for technology implementation. However, schools throughout the country chose to implement different technology, in different numbers, for a myriad of different uses (Sahin, Top, \& Delen, 2016).

In order to combat unequal access to technology in classrooms, emphasis has transitioned to providing each student with access to an Internet-capable device. Initially, known as the 1:1 student to device initiative, this push took place in private affluent schools. Windschitl and Sahl (2002) conducted an early examination of a 1:1 initiative in a private middle school that required that each student purchase a laptop. This study found significant increase in test scores before and after implementing this initiative.

The NCLB Act had the primary aim of increasing student achievement in schools. When studies such as the Windschitl and Sahl (2002) study proved that 1:1 initiatives had the potential to increase student achievement, public school districts began their own 1:1 initiatives. Educational researchers Harris, Al-Bataineh and Al-Bataineh (2016) completed a case study of two fourth grade classes within the same public school; one that had integrated laptops at a 1:1 ratio and one that only had four desktop computers for the class to share. The researchers aimed to decipher whether laptops at a 1:1 ratio increased student achievement through comparing test scores between the classes. Harris and colleagues (2016) found that the average test scores in the 1:1 class were $82.58 \%$ versus $65.87 \%$. in the non-laptop class.

With proof that technology at a 1:1 ratio had the potential to increase student achievement, districts began the search for which form of technology to implement in classrooms. Early in this process popular choices included Chromebooks, iPads, laptops and 
android tablets (Demski, 2012). In a 2012 study, Demski (2012) interviewed officials from a plethora of school districts that had launched 1:1 initiatives regarding how the choice about which device to implement was arrived at. Among those chosen for the interview were superintendents, directors of educational technology and technology implementation coordinators. From these interviews it was found that price point was the number one factor in making these decisions.

Demiski (2012) also discovered that, among the different districts included in the study, the device implemented most was the Chromebook, a laptop-like device with a touchscreen, for its low price point and high durability. Subsequent studies verify that Chromebooks are edging out other devices in 1:1 initiatives. In an article published in 2015, it was asserted that Chromebooks are being implemented by many districts because they are durable, have a built-in keyboard, utilize a single login for access to all Google applications, store files online and run applications from the Internet (Schaffhauser, 2015). This information demonstrates that, while those in charge of making decisions regarding device implementation choose Chromebooks primarily because of their low price point, Chromebooks have many advantages for classroom usage. Because the Chromebook is a durable device existing in a margin between being a laptop and a tablet, students are able to move around the classroom and the school with the device. This enables students to gain access to the abundant knowledge accessible on the Internet from a variety of locations.

When technology in classrooms became an expected norm, educational technology researchers transitioned to asking questions regarding how to best implement technology in teacher's teaching practices. In 2005, Peggy Ertmer, a professor of educational technology at Purdue University, conducted interviews with teachers that both embraced and rejected 
technology in their teaching practices. Ertmer (2005) found that the largest factor in teachers actively implementing technology in their teaching practice was the teachers' attitudes, which were informed by past experiences with technology.

In order to further expound the experiences that inform attitudes, Ertmer (2005) breaks experiences into three subtypes: personal, vicarious and social-cultural. In relation to teacher beliefs regarding technology in the classroom, personal experiences refer to a teacher's previous experiences with technology and education (Ertmer, 2005). For example, has the teacher utilized technology in his or her own education? Was it helpful? Or, how have other forms of technology been integrated into a teacher's classroom? Has the teacher received support with this integration process? Vicarious experiences with technology refer to the ways that teachers perceive technology as being beneficial, or not, in others' classrooms (Ertmer, 2005). Does the research show that technology increases student achievement or motivation? Lastly, Ertmer (2005) asserts that social-cultural teacher experiences with technology refer to the teacher's school atmosphere. To understand a teacher's social-cultural experiences, one would aim to understand the way that the school dynamic values or devalues technology within the classroom. This discourse places agency of successful technology integration onto the teacher and exposes underlying experiences that influence a teacher's complex feelings towards technology.

In 2016 a study was conducted to evaluate 553 teachers' attitudes toward Chromebooks before implementing them in their $6^{\text {th }}-12^{\text {th }}$ grade classrooms, versus one year after the implementation (Sahin, Top, \& Delen, 2016). Prior to implementation, the majority of teachers interviewed expressed excitement toward implementing Chromebook technology, as they believed the devices would positively impact student achievement and motivation. However high censorship of helpful websites, unforeseen technological problems, the Chromebooks being 
distracting for students and the disappointment of expectation versus reality regarding Chromebook integration lead to decreased teacher optimism towards integrating Chromebooks in their teaching practice (Sachin et al., 2016). This demonstrates that complex factors influence teacher attitudes. Therefore, the way that a teacher integrates technology into his/her teaching practice is not the sole result of his/her attitudes, but also a result of experiences that influence these attitudes.

In order to normalize teachers' usage of technology implementation in their classroom practice, educational technology theorists began shaping concrete frameworks to conceptualize teachers' technology integration. The most widely utilized of these in the academic community is Kohler \& Mishra's (2013) technology, pedagogy and content knowledge (TPACK) framework. This framework asserts that, through a comprehensive understanding of a teacher's knowledge of content, personal pedagogy and technology, one can understand how and why a teacher implements technology.

Another newly emerging framework is Puentedura's (2016) substitution, augmentation, modification and redefinition (SAMR) model. The SAMR model is divided into four tiers. Within the model, these tiers stack on one another and the goal is for teachers to move their use of classroom technology upward, away from substitution and toward redefinition. According to this model, substitution refers to utilizing technology as a means of a direct tool substitution. An example of technology use at the substitution level would be using the notepad function on a laptop or tablet device, which does not contain a spelling/grammar check feature to replace pen and paper for note taking. Next comes the augmentation tier, which refers to using technology as a tool substitution with functional improvement. For example, a student utilizing Microsoft Word, with spelling and grammar check, to compose an essay rather than pen and paper would 
be an augmented use of technology. The third tier is labeled modification, meaning that the integration of technology redesigns classroom tasks. A classroom activity at the modification tier would be an activity in which a teacher, rather that asking students to make posters about volcanoes as they have done in years prior, invites students to create an Adobe Spark presentation about volcanoes. The highest tier in the framework is termed redefinition, meaning that the integration of a new technology enables previously inconceivable learning opportunities. During a unit about space, providing students with a NASA link to observe satellite images in real time would be a classroom activity at the redefinition level. Unlike the TPACK framework that is utilized by educational technology academics, the SAMR framework is often utilized at teacher training seminars to explain how to best implement technology in the classroom. Puentedura himself has not published any academic research on this model. Rather, information regarding the SAMR model from Puentedura comes from slides that he has posted on his blog, hippasus.com, from various keynote speeches that he has conduced.

Other authorities in the field of educational technology have published research regarding the limitations of the SAMR model. Hamilton, Rosenburg and Akcaoglu (2016), assert that, like the TPACK framework, the SAMR model has the limitation that it does not take into account school context or supports that teachers receive as a factor leading to decisions regarding technology integration. Also, Hamilton and colleagues (2016) assert that the structure of the SAMR model is too rigid; the substitution tier is not innately inferior to redefinition. Rather, different utilizations of technology are appropriate for different tasks. While the TPACK framework is highly theoretical, the SAMR model is too centralized in practice and does not ask questions regarding why teachers utilize different tiers of technology implementation. 
While research findings in the post-NCLB period operate under the assumption that technology, by virtue of its ability to provide each student with the insurmountable knowledge available on the Internet, post-NCLB discourse holds the assumption that technology in the classroom should improve teaching in some way. Both of these frameworks give responsibility to the teacher in successful implementation of technology into classrooms. However, these two popular frameworks omit the underlying factors that lead to the way that teachers choose to carry out technology implementation in their classrooms.

In addition to grappling with questions about whether or not technology can/should be a classroom tool, teachers face the challenge of instructing students with different learning needs and preferences. In both educational theory and practice, there have been many pedagogical approaches and belief systems that have emerged in response; with pedagogical beliefs referring to the way that a teacher conceptualizes his/her own teaching and practice of teaching. A strengths-based pedagogical approach that has become increasingly popular, termed "differentiated education", has the primary aim of individualizing learning outcomes and teaching strategies in response to each unique student's idiosyncratic personality, characteristics, values, needs and desires (Tomlinsom, 2014). The primary aim of the differentiation as a pedagogical belief is that teachers can empower all students to learn through providing different learning avenues.

While differentiating instruction is, by no means, the only approach utilized by teacher in response to the diverse needs of students, it is an approach that is often utilized in tandem with technology integration. In a book published in 2014 titled The differentiated classroom: Responding to the needs of all learners, author Carol Tomlinson asserts that technology can be a 
useful tool in actualizing differentiation aims because each student can be given a different assignment that is targeted to his/her individual learning needs.

A common critique of differentiated education is that it pushes all students in different directions, rather than focusing on the standards set in place by policies such as The NCLB Act. However, in many guides for achieving differentiated classrooms, such as Tomlinsons's (2014) book, this critique is remedied through utilizing individual tactics to work toward federal, state and school-specific standards. Unlike other pedagogical frameworks, differentiated instruction does not assume that achieving these standards is the penultimate goal for all students. Rather, this model asserts that, for students that do not achieve these standards, progress is still success. Also, for students that these standards may come easier to, pushing beyond the standards toward more abstract models is the mark of success. Thus, integrating technology and having the capacity for students to be completing a plethora of different assignments simultaneously demonstrates that technology can be a useful tool in assisting teachers in achieving differentiated classrooms.

In the seventeen short years following The NCLB Act, a paradigm shift has occurred. Prior to the act, the educational technology discourse community asked questions regarding whether or not technology belonged in classrooms. However, The NCLB Act seeded the assumption that technology implementation would increase student achievement. After a process of probing for the best technology, Chromebooks rose as the star pupil for the 1:1 initiatives that have come as a result of this technology surge. Today, the educational technology discourse community is still in the process of searching for a way in which to discuss and evaluate how teachers have implemented technology in their teaching practice. In addition, concrete frameworks have yet to capture the complex and individual nature of the way that teachers' 
experiences with technology lead to the formation of attitudes that inform technology integration decisions.

\section{Gaps in Current Research}

Current research omits the unique demographics of the different schools studied. Often, the current research takes place in private schools or medium to high-income public schools. The unique needs of increasingly diverse student populations are not accounted for in the current research. Thus, this research has the aim of describing, in detail, the way that one teacher has integrated technology in her classroom in response to the diverse needs represented within her Title I classroom.

While the current research demonstrates that technology has the capacity to increase student achievement, qualitative research is needed. More specifically, the aim of the current discourse is to place agency on teachers for successfully achieving technological integration without describing what successful technology integration looks like in practice. While the aforementioned studies state that technology was or was not implemented, little description explains the sites that are used. This study aims to describe the specific sites utilized in the case study classroom with descriptions of the lessons made possible by the technology.

In the current research the impact that teacher's pedagogical frameworks have on their decisions regarding technology integration are also unaccounted for. Therefore, this research aims to describe the participant teacher's unique pedagogical framework and the way that this underlies her decisions regarding the integration of technology. 


\section{Current Study}

This research utilizes case study methodology to observe one teacher, Mrs. Welsh (pseudonym), and her fourth grade classroom within a Title I school that has integrated Chromebook technology at a 1:1 student to Chromebook ratio. This research has the primary aim of describing the teacher's views regarding her goals for students within her classroom. Then, this research aims to describe the way that Chromebooks are utilized to work toward achieving these goals. Within this aim this research will describe specific sites and activities utilized by the teacher. Thus, this research aims to answer the research question: How is one teacher utilizing Chromebooks at a 1:1 student to device ratio in accordance with her own personal pedagogical beliefs?

The intention of this study is not to assert that the technology usage methods that the participant teacher employs are superior and should therefore be implemented by every educational professional; this research is not evaluative in nature. Rather, this case study will describe how one teacher has utilized technology as a tool according to her pedagogical beliefs regarding how to best serve her students. In addition, it is expected that first year teachers entering the teaching profession are, at the very least, computer literate. This study has the aim of providing an example for both current and future teachers of the way that a teacher has implemented technology according to her personal pedagogical beliefs in order to assist other educators to process the way that technology could be a tool in achieving the aims presented by their own pedagogical beliefs. 


\section{Methodology}

The subsequent research procedures were approved though Portland State's Institutional Review Board (IRB) as of July 2017.

This study was conducted over a fourteen-week period that began at the start of the 2017 school year, the second week of September, and ended just before winter break, the third week in December. As the researcher, I spent a total of twenty-six days within the classroom. On Mondays and Wednesdays each week, I was present in the classroom between 8:00 am and 1:00 pm.

In addition, two interviews were conducted with the teacher in order to understand the unique pedagogical lens that she brings to her classroom and the way that technology was used as a tool in working toward these aims. These interviews were around half an hour each. One was conducted in week five of my classroom observation and the other was conducted in week fourteen. These interviews were recorded and transcribed. Then, they were analyzed and threaded throughout my analysis as a way of incorporating the teacher's perspective through reflective, personal statements regarding her perspective.

\section{Sample}

In order to deeply understand the way in which classroom technology was being utilized in one classroom, this research utilized a case study methodology of one teacher and her class.

The chosen class for this research was a fourth grade class within a Title I school. Both the school and the district chosen for this case study will remain anonymous in order to protect the participants of the study. According to the district's 2016 report of the school, the school has a diversity breakdown of 33\% Asian or Pacific Islander, 32\% Hispanic, 26\% White, 3\% Black, $1 \%$ American Indian and 5\% of students of other races, including multi-racial. In addition, the 
school demographics section of the school's report card state that $50 \%$ of the students are listed as economically disadvantaged. In addition, this report shows that $38 \%$ of the student population are English Language Learners and $25 \%$ of students are listed as mobile students, meaning that students switch from school to school for reasons other than normative grade progression. Lastly, $12 \%$ of the school population are students with disabilities ("School and District Report Card," 2016). This research holds the assumption that the role of teachers is to cater teaching practices to the needs of the student population that they serve. Thus, in understanding the population served by the school, one can better understand the teacher's pedagogical decision-making process.

The participant teacher for this study will be referred to under the pseudonym "Mrs. Welsh.” As part of a district initiative, Mrs. Welsh's class had transitioned to a 1:1 student to Chromebook ratio over the last couple years.

As the Ertmer (2005) research asserts, teacher beliefs and attitudes are a vital factor in predicting successful technology integration. Thus, the fact that Mrs. Welsh's class had technology implemented and available for student usage in combination with her inclination toward technology as a previous computer teacher informed my decision to choose Mrs. Welsh's classroom to conduct this research.

\section{Role of the Researcher}

Within Mrs. Welsh's classroom I fulfilled dual roles. The first of these was that of a researcher and the second was that of a practicum student, learning how to be a successful classroom teacher. In order to harmonize these two roles, I acted as a participant-observer within the classroom.

While I was in the classroom, I assisted where I was needed, including reading and math 
assessments, small group work and whole class instruction-- acting in my role as a practicum student. However, when technology was being utilized in classroom tasks, I assisted with the task at hand while also taking brief notes about the activity. Then, when I returned home each day, I would look at these notes to complete a detailed, retrospective write-up of the technology usage for the day.

\section{Data Collection}

Prior to beginning classroom observation written consent was obtained from the participant teacher. Within the first week of the school year, assent for the study was obtained from students. At the school's back-to-school night, parental consent was obtained from the parents that were present. Consent from the remaining parents was obtained through sending home consent forms with the students and having these returned to me during school.

For this research, the notes from the days spent in the classroom were analyzed. Each week, I took brief notes within the classroom regarding technology uses. These notes were then used to complete write-ups of the different technology uses. Each week, these write-ups were turned into memos that included both my classroom observations and analysis of these observations. These memos were sent to my thesis advisor whom sent me feedback on the observations.

From classroom observation, it was found that Mrs. Welsh utilized several websites/apps regularly with the classroom technology; these were Khan Academy, DreamBox, Bookshelf, Google Classroom and Seesaw. When I began to see this pattern (around week four) I created a chart organized by site/app that was further broken down by week-- this was also sent to my adviser weekly. 
In addition, two interviews were conducted with Mrs. Welsh in which she was asked questions regarding her pedagogy, technology integration, sites utilized and follow- up questions from the observation. These interviews were recorded and transcribed, and then the recordings were deleted, as per Institutional Review Board (IRB) direction.

\section{Data Analysis}

The data considered for analysis for this research included the write-ups of each day in the classroom, the site usage chart and interview transcriptions. All of this was coded for analysis in order to understand the relationship between the teacher's pedagogical beliefs and the decisions that she made regarding Chromebook usage.

First, I reviewed common themes within the interview transcriptions regarding the teacher's beliefs about education. These interviews were open coded for the attitudes underlying Mrs. Welsh's teaching practice. From this, I came to the conclusion that the teacher was utilizing Chromebooks as a tool in differentiating her classroom and creating an environment in which each student had something individually catered to work on. Then, questions related to the different sites, namely Khan Academy, DreamBox, Bookshelf, Google Classroom and Seesaw, were also open coded in order to understand the way that the teacher was using these sites to work toward her pedagogical aims. The common theme among the usage of these sites was that each one enabled the teacher to assign appropriate material to all students.

For the observation notes and chart, this data was compiled in order to assess common themes among different uses of each site. This information was coded by site and functionality. Common themes included setup, individualized instruction and whole- class instruction. This information was utilized to understand frequency and functionality of the use of the different 
sites observed. This data was coded to parse out the functionality of different sites in the context of the teacher's aim of differentiation.

\section{Results}

Through classroom observation and teacher interviews, it was found that Mrs. Welsh utilized 1:1 student to Chromebook technology, and more specifically the sites Khan Academy/DreamBox, Bookshelf, Google Classroom and Seesaw, in order to bring her personal, pedagogical frame of differentiation into practice in her fourth grade classroom.

\section{Pedagogical Beliefs of the Participant Teacher}

As this research aimed to illustrate Mrs. Welsh's pedagogical frame, it became important to ask Mrs. Welsh herself to voice her goals for the students in her classroom. During an interview, this question was asked of Mrs. Welsh; her response reflected that she believes that her role, as a teacher, is to aide each student in taking ownership of his/her own learning through self regulation and claiming agency in learning. This was evident in Mrs. Welsh's response: My overall goal for all of my kids is to make them more independent-to make them see that their learning is their responsibility and not the teacher's.... I want them to see that they are able to change things and take charge of their learning outcomes...Really, my overall goal is to have my students take charge of their own education.

In addition, as stated by Ertmer (2005) teacher beliefs and values regarding technology integration are the largest factors in predicting the success of any classroom technology. Thus, it becomes important to understand how Mrs. Welsh views the role of technology in actualizing her pedagogical beliefs. In an interview, Mrs. Welsh explained that technology is not going to force each student to take the wheel of his/her educational journey, but that it can guide the student toward this aim. This is the function that Mrs. Welsh sees technology holding in her classroom. This was vocalized when Mrs. Welsh stated in an interview: 
Technology isn't going to solve every problem, so if you are looking at what your students need and technology is an answer for some of that, use it. If it's not, if it makes more sense to have students using paper and pencil or talking to each other or using a whiteboard, which I guess is some kind of technology, do that. You should look at what students need and look for the best tools to assist with that. Don't look at the technology first, look at the need first and it should all naturally fall into place if you are focusing on what the targets are.

Mrs. Welsh also expressed technology being useful in allowing her to allot her time to attend to individual student needs, while also having the peace of mind that all students have something appropriate to work on while doing this. This ability for each student to have work that pushes his/her understanding further is differentiation at its core. This was evident when Mrs. Welsh reflected:

I can teach what I want to teach when I want to teach it. It is not about not having the technology to do it. What is really nice about this is that I can do a lot of group work and a lot of targeted individual work because I know that the kids have something to work on at their level-- they have resources in front of them and they don't have to sit around and wait for me.

Throughout this research, it became evident that Mrs. Welsh saw utilizing technology according to the post-NCLB discourse-- as a natural succession to the fact that today's students have grown up in a computer-literate world. To this point, Mrs. Welsh stated:

This is the age. These kids grew up with computers and they know how to use them as tools. It isn't novelty enrichment; we are teaching basic curriculum on Chromebooks. It's not like it was when I was first in teaching. It isn't an extra thing. We are using computers to teach reading, to teach writing, to teach math, to teach research. I'm not saying it's a replacement for the pen, for paper, but it is definitely an important tool we are using to teach.

In summation, through Mrs. Welsh's words, it becomes evident that she has the aim of differentiating her teaching in order for each student to work toward being a more independent learner. This demonstrates that, according Mrs. Welsh's perspective, her role as a teacher is to help students to work towards taking agency over their learning, through differentiating to each student's specific needs. It is also clear that Mrs. Welsh views technology not as a supplementary novelty, but rather as a critical tool in teaching all subjects. 


\section{Functionality of Chromebooks as Classroom Technology}

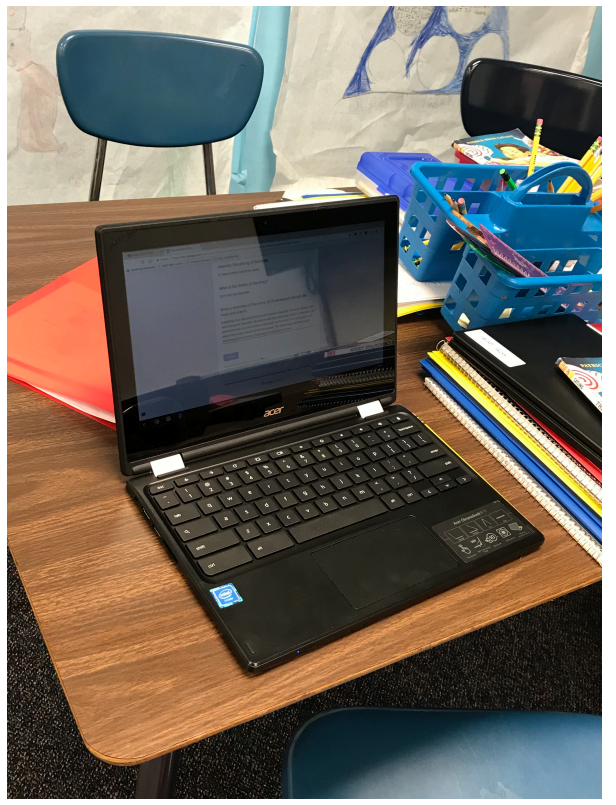

Figure 1. Chromebook in upright orientation

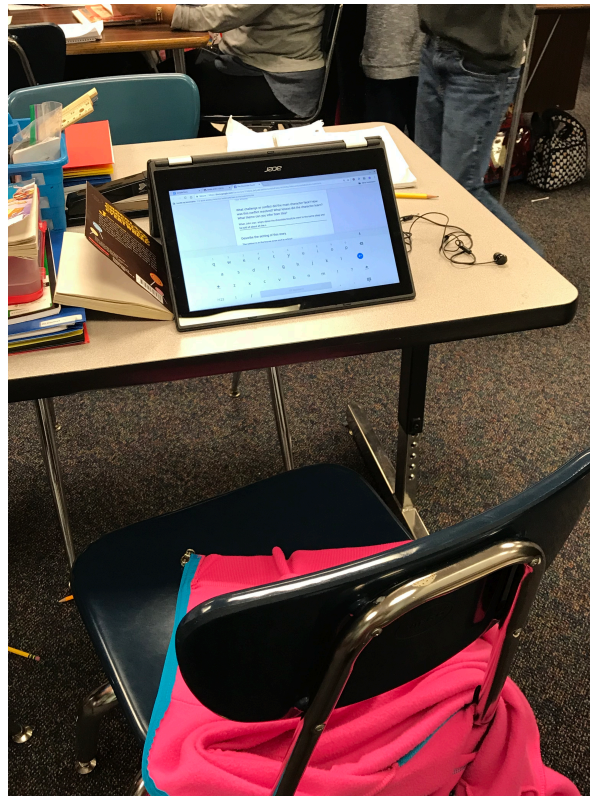

Figure 2. Chromebook in folded orientation

Chromebooks were utilized all twenty-four days of this study's duration. In the first week of the school year, Mrs. Welsh assigned numbers to each student within the classroom that correlated to the Chromebook that they were assigned. As a result of each student always gaining access to the same Chromebook, each student was able to choose a background and log-on image of his/her choice.

The functionality of the Chromebooks in the first week and a half of school was ensuring that each student could navigate to the sites that would be utilized throughout the year. Also, black folders were passed out to each that contained the passwords that they would use to log onto each site. While the folders were distributed, students were instructed to not share passwords with one another.

Sent home with the students within this first week of the year was a form to be signed by parents that granted online permissions. The intention of this form was to gain consent for 
photographs to be posted of the students online and to also gain consent for the student to utilize Google sites.

Ensuring that each student had access to headphones or ear buds to be utilized with their Chromebooks presented a challenge at the start of the year. This was an item requested on the school supply list for the year. However, Mrs. Welsh shared that, each year at this school, less than half of the students brought all of the supplies requested due to the financial strain. In addition, there was some confusion for families whose primary language was not English with the language of "ear buds" on the supply list that lead around five students in the class to bring Q-Tip ear cleaners rather than headphone ear buds. As a result, Mrs. Welsh, out of her own pocket, purchased ear buds for over half of the class.

Prior to this school year, the fourth grade classrooms had all been located within the outside portable classrooms of the school. Last minute classroom shifts left Mrs. Welsh with tables rather than desks. In response to this challenge, Mrs. Welsh made the decision to try out more flexible seating; thus, students were often shifting supply boxes, book boxes and

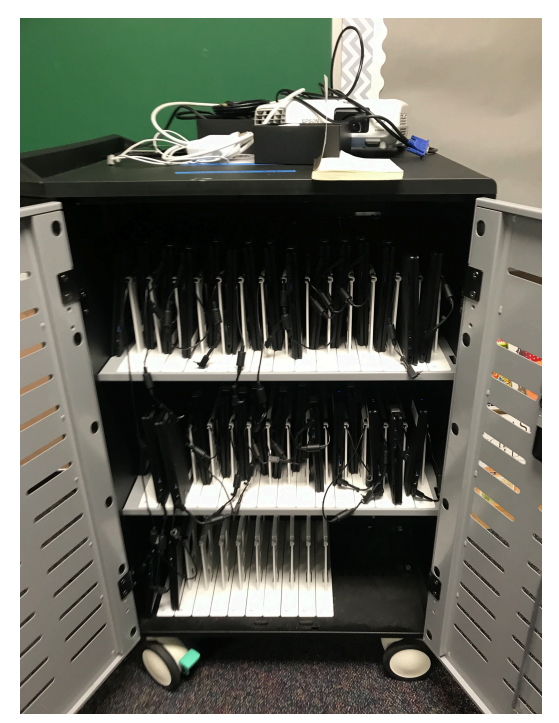

Figure 3. Classroom, Chromebook cart Chromebooks from place to place through the room. Depending on activity, personal preference and location within the classroom (table versus floor for example) the student could adjust the orientation of their Chromebook. See Figure 1 and Figure 2 that present photographs of different Chromebook configurations employed by students in Mrs. Welsh's class.

Throughout the majority of the study duration, students kept their Chromebooks on their tables when they were not in use. However, at the end of the day or when Mrs. Welsh did not plan on making use of the devices for the remainder of the day, the Chromebooks were placed 
into the correct cubby of a Chromebook cart. When the student put his/her Chromebook away for the day, he/she also plugged it in to ensure that it was charged and ready for the next day. Once all Chromebooks were put into their numbered cubby, Mrs. Welsh locked the cart. See Figure 3 for a photograph of Mrs. Welsh's classroom, Chromebook Cart.

Khan Academy \& DreamBox as a Math Tool

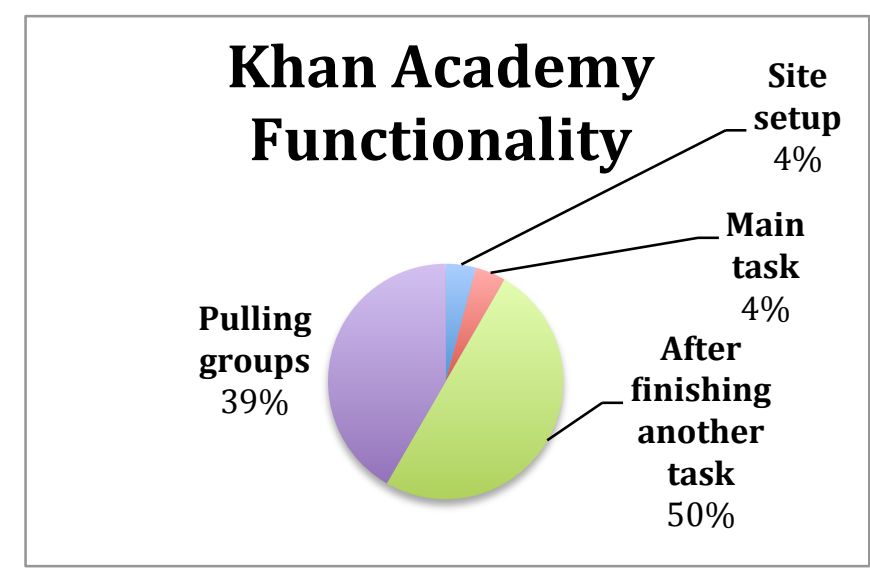

Figure 4. Khan Academy Functionality

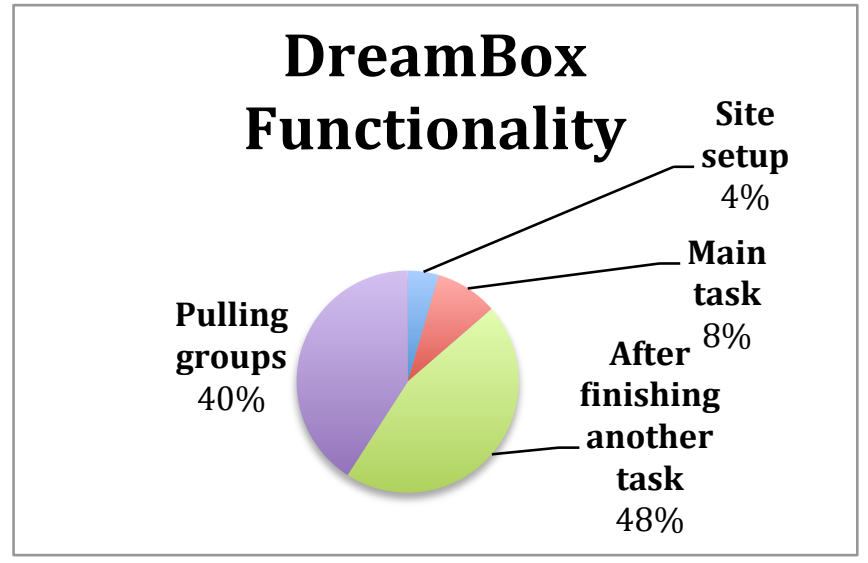

Figure 5. DreamBox Functionality

Both Khan Academy and DreamBox were utilized during math time to differentiate math instruction in Mrs. Welsh's classroom.

Khan Academy is a free site that allows students to access standard-aligned content. From this site, teachers are able to assign topics and track student progress ("How Khan Academy Works," n.d.). In line with Mrs. Welsh's intention of helping each student to take ownership of his/her own learning, Khan Academy states the intention of fostering a growth mindset and helping students take ownership of their learning through immediate feedback ("How Khan Academy Works," n.d.). Mrs. Welsh explained that this is a site that she has been utilizing for many years, both as a computer teacher and a classroom teacher. While Khan Academy has the ability for students to work on math, science and engineering, computing, arts 
and humanities, economics and finance, test prep and college/career prep, this site was used solely for math in Mrs. Welsh's fourth grade classroom.

In total, Khan Academy was utilized twenty-four out of twenty-six days ( $~ 88 \%)$ of the study duration. One of these utilizations $(\sim 4 \%)$ of the site was for setting up the site and ensuring that all students could log onto their accounts with the usernames and passwords provided by the school. Twelve of the twenty-four times (50\%) the site was utilized within the class, students only had the option to go onto Khan Academy after finishing another task/assignment. Once ( $4 \%)$ Khan Academy was utilized as the primary math lesson of the day. During these times, each student had an individualized math assignment that was formulated through an assessment given by Khan Academy. Ten of the twenty-four times (42\%) that Khan Academy was used Mrs. Welsh and/or I was pulling groups or individual students to work on different tasks/assignments. During these times, Khan Academy was not a primary or secondary priority, rather it was just one of the many things going on within the classroom. During these times, not only did all of the students have a differentiated math assignment, but students that could benefit from one-on-one or group instruction were also able to get this-while their classmates also had something beneficial to work on. See Figure 4 for a visual representation of this data.

DreamBox was another online math tool that was utilized in Mrs. Welsh's class for math. Unlike Khan Academy, this was Mrs. Welsh's first year of using this site as a math tool. It was the school district that made the decision that elementary schools would begin utilizing DreamBox in math. On the DreamBox website, it is stated that DreamBox helps teachers to "understand the unique needs of every student and use real-time insight to make the best instructional decisions" ("Why DreamBox," n.d.). The intention of this site is to be adaptive to each student utilizing the site. As students complete math problems, the site analyzes 48,000 data 
points per student, per hour in order to quantify student understanding and optimal learning ("Why DreamBox," n.d.). In addition, this site utilizes visuals and auditory instruction in both English and Spanish. Like Khan Academy, DreamBox also aligns lessons to state, national and common core standards. Unlike Khan Academy, DreamBox does come at a cost of $\$ 20.00$ per student per year (“Why DreamBox," n.d.).

According to both the teacher and the study findings, DreamBox had similar functionality to Khan Academy within the classroom. The delineation of the sites comes from each site employing different teaching tactics to achieve similar goals. Through this site, the teacher assigned topic and DreamBox scaffolded the lesson in response to student achievement. However, it was imperative that students wore headphones while utilizing DreamBox because the instructions for the problems were given to students orally. I was instructed by Mrs. Welsh that if a student were to ask for assistance while working on a problem on DreamBox, to tell the student to put in his/her headphones and listen carefully to the instructions. I did not observe any occasion in which the student was still unable to complete the problem after following this instruction. Unlike Khan Academy, which most frequently asked students to type in numerical answers, many of the problems on DreamBox asked students to manipulate various math models on their screens in different ways. Therefore, both Khan Academy and DreamBox were assistive tools in differentiating math instruction, however the two sites had different teaching styles within this comparable aim.

In total, DreamBox was utilized twenty-two out of twenty-six days ( $\sim 84 \%)$ of the study duration. One of these utilizations $(\sim 5 \%)$ was for setting up the site and ensuring that all students could $\log$ on with the passwords provided by the school. On two occasions ( $\sim 9 \%)$, DreamBox was the main math lesson of the day. Ten of the twenty-two times $(\sim 48 \%)$ that students were 
instructed to go onto DreamBox was after they had finished another assignment. Nine of the twenty-two times $(\sim 40 \%)$ that DreamBox was utilized, the teacher or I were pulling groups of students to work on different tasks/assignments. During these times, DreamBox was not a primary or secondary priority, rather it was just one of the many things going on within the class. See Figure 5 for a visual representation of this data.

In the interview conducted for this study at the start of the year, DreamBox was still very new to the teacher, but she noticed quickly that with DreamBox, Some of the students really like it and some won't put their headphones on when they are using it - they ask for help and I say no. That might be the benefit to having the two programs-they teach to different learning styles.

In the interview toward the end of the study, Mrs. Welsh had come to the conclusion that DreamBox and Khan Academy are designed for different learners. In this interview she stated:

DreamBox is very oral. It's very much built on having to have headphones to even complete an assignment. DreamBox does walk them through. So, maybe for the kids that need more support, DreamBox might be more useful because it very slowly walks them through-they do have to listen though. They have to have those headphones in and be listening to what it's telling them to do. But, I do think DreamBox has more scaffolding. Khan Academy, I think, maybe for the higher kids. If they know, "hey I don't understand this, I am going to watch the video and view the hint," and they have that independent habit where they know what to look for and do that, then they can do it by themselves. Maybe DreamBox forces them to do those things, even when they may not need it. So maybe it is per kid, which one is better? But, I do see my lower kids able to follow DreamBox easier.

This information demonstrates that both Khan Academy and DreamBox aided in Mrs.

Welsh's ability to differentiate her math instruction. Both of these sites enabled students to have math assignments catered to individual needs. Also, in knowing that each student had the capacity to complete this individualized learning without the aid of a teacher, Mrs. Welsh and I were freed up to analyze student progress in math and work with small groups and individual students that could benefit from more individualized, focused instruction. While both sites served similar functionality, the discongruity between the two came from both of the sites appealing to 
different learning styles — thus allowing the sites to work symbiotically, rather than redundantly, in their functionality of differentiation. This is evident through the similarity between the functionality of the two sites illustrated in Figure 4 and Figure 5.

\section{Bookshelf as a Reading Tool}

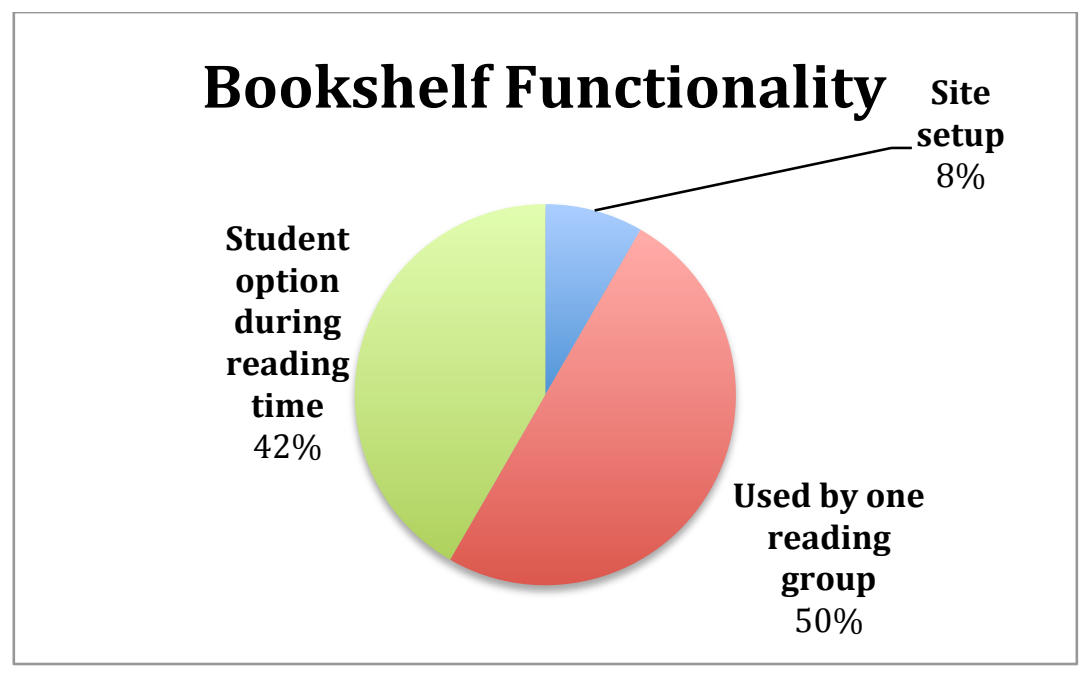

Figure 6. Bookshelf Functionality

Bookshelf is an eReading organizer created by The American Reading Company that organizes eBooks according to Independent Reading Level Assessment (IRLA) levels ("Bookshelf: About," n.d.). Through the site, the district purchases access to eBooks for all students in the district. Therefore, Bookshelf itself is a free tool, but licenses to the eBooks do require district expenditure. Once the district purchases books, all students within the district are able to read, organize and look through these books according to IRLA level.

In Mrs. Welsh's classroom, Bookshelf was utilized for students to have access to a wide breadth of reading material of different genres at their IRLA levels. Thus, when Bookshelf was utilized, students were able to self-regulate through finding reading material appropriate to their IRLA level, interests and individual reading goals. Mrs. Welsh, in an interview, expressed that this functionality was particularly useful for students at lower reading levels: 
Where I think it [Bookshelf] is really helpful is with the kids that are at lower reading levels. I have the one kid that is at a kindergarten level, green, and those books she would read in one setting. Then I have kids at the first and second grade levels. The volume that those kids need, they would burn through several books in a day, and so, that gives me another pot of books that they can read them because they go through them so fast. When you are reading at a fourth grade level, a novel it's going to take you a week or so. So, at the lower levels it is really helpful.

Bookshelf was utilized twelve out of twenty-six days $(\sim 46 \%)$ of the study duration-See Figure 6 for an illustration of the functionality of Bookshelf in Mrs. Welsh's classroom. One utilization $(\sim 8 \%)$ of this site was for setup and ensuring that all students could log on with the passwords provided to them by the school.

During weeks seven, eight and nine, students were placed into reading groups that correlated with their reading ability as determined by the results of Mrs. Welsh testing each student to discern his/her IRLA level in the previous weeks. The group with the lowest IRLA score consisted of three students, all that were tested reading at a first to second grade IRLA level. Each of these students was asked to select books of interest that were at his/her reading level on Bookshelf. This accounted for six of the twelve times $(50 \%)$ that Bookshelf was observed being utilized. Also, during book group time, Mrs. Welsh conferenced with each student to discuss his/her IRLA level, and the steps that would lead them to the next level. For some students, this meant reading a breadth of genres at his/her IRLA level. Bookshelf was presented as a way of searching for books according to level and genre in order to achieve each student's differentiated reading goals. The process of utilizing Book Shelf during book groups enabled Mrs. Welsh to achieve collaborative differentiation.

Throughout the study duration, there were five occasions ( 42\%) in which Mrs. Welsh presented reading on Bookshelf as an option during silent reading time. The majority of these occasions occurred in the days following the IRLA conferences. Throughout the study duration, 
less and less students were observed making the choice to utilize the site during their reading time.

It becomes important to note that each day that Bookshelf was utilized, only some students utilized the site. Never was the whole class accessing Bookshelf at the same time. This demonstrates that, while it was proven that Bookshelf could be utilized as a tool in differentiating reading instruction, Mrs. Welsh did not use this site arbitrarily for the sake of utilizing technology. Rather, as part of differentiation aims, Mrs. Welsh utilized Bookshelf's technology when it aided in addressing an observed disparity of reading material for students at lower levels. After conveying individualized reading goals to students, Bookshelf was also introduced as a tool that students could access, both at school and from their home computers, to work toward these goals.

During the final interview for this research, Mrs. Welsh expressed her intention of using Bookshelf more frequently later in the school year. In order to ascend IRLA levels, it is a requirement to read level-appropriate books of varying genres. Thus, when students begin working at these targeted goals, she believes that Bookshelf will be utilized more regularly. This demonstrates that Bookshelf, particularly in Title I schools where there may be access to fewer books within classroom, can be a useful tool in aiding students in ascending reading levels through accessing a wider breadth of books. 


\section{Google Classroom as a Writing Tool}

\section{Google Classroom Functionality}

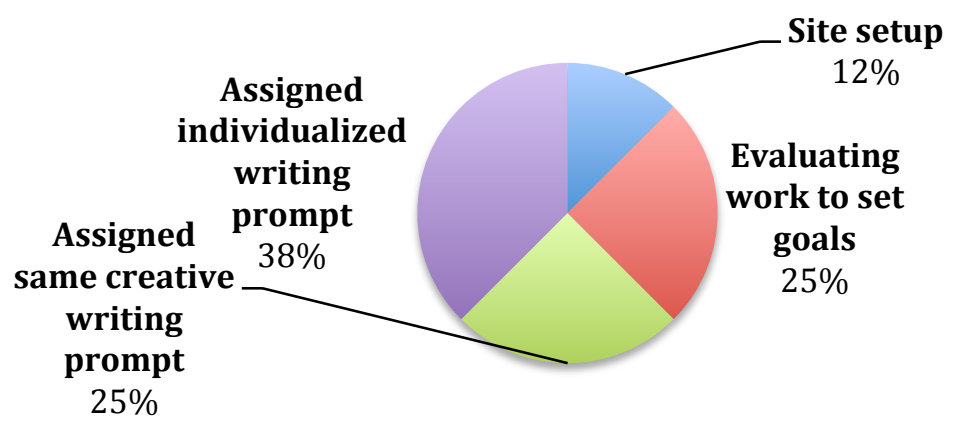

Figure 7. Google Classroom Functionality

Unlike other sites utilized in Mrs. Welsh's classroom, Google Classroom is free to all users ("Google Classroom FAQ," n.d.). When one logs onto the site, the description of the site reads: "Classroom is a free web service for schools, non-profits, and anyone with a personal Google Account. Classroom makes it easy for learners and instructors to connect—inside and outside of schools" (“Google Classroom: FAQ," n.d.).

Through Google Classroom, teachers are able to paperlessly collect work from students as well as share links and announcements ("Google Classroom: FAQ," n.d.). Primarily, Google Classroom was observed in this case study as a means of assigning writing samples and easily collecting and printing these samples. In an interview, when reflecting on her use of Google Classroom, Mrs. Welsh explained that she prefers reading student writing samples that are typed because she can tell when students mean to use different punctuation and capitalization. She also expressed noticing that she receives both more quantity and quality writing when the assignment is typed.

According to Mrs. Welsh, assigning writing assignments through Google Classroom had particular benefits over assigning the writing sample either through handwritten means or 
through Google Docs, Microsoft Word or another similar program. In an interview, when reflecting on the choice to use Google Classroom over other typing programs, Mrs. Welsh explained that she can assign a writing sample, the student can respond, and it all goes to one location in which each student response can be printed at the same time. The opposite was true when she was using Google Docs and all students had to share a link with her - completed samples would get lost into the unforgiving depths of the Internet. Mrs. Welsh stated:

With Google Classroom I can print them [student writing samples] all out at once. When I do, I end up with a blank page in between, but I take those out and feed them back into the printer afterwards. I do like to have a printed copy that I can mark up for more formal writing assessments. Otherwise, I just put some comments for them to see online and I never print it out.

In total, Google Classroom was utilized eight out of the twenty-six days $(\sim 31 \%)$ of the study duration for the purpose of student writing samples. See Figure 7 for an illustration of the observed utilizations of Google Classroom in Mrs. Welsh's class. One of the eight employments of Google Classroom $(\sim 13 \%)$, the site was utilized for setup in the first week of school with the assistant of students' black, password folders.

During two of the eight times (25\%) that Google Classroom was utilized for writing samples, assigned writing prompts were centered upon evaluating personal work in order to set future goals. An example of this was that, after recording themselves conducting a personal speech, each student was asked to re-watch his/her speech and answer questions about what they did well and what could be improved upon for future speeches.

In two of the employments of Google Classroom (25\%), students were assigned the same writing prompt. For example, Mrs. Welsh told the class a story about a time that her dog knocked down her Christmas tree. Then, because the class had been discussing literary perspective, Mrs. Welsh asked all of the students to rewrite the story through the dog's perspective. It is important 
to note that, while all students were working on the same assignment these two times, students (especially English Language Learners) were given more assistance with the assignment.

Three of the instances in which Google Classroom was used ( $38 \%)$, students were given individual writing prompts based on his/her specific reading goals as determined by IRLA level. An example of this was that, after reading the book The Chocolate Touch, students were given different writing prompts based on the goals of their IRLA level. For example, IRLA at the fourth grade level focuses a lot on character traits and character development. Therefore, students at this IRLA level were assigned a prompt that focused on recognizing aspects of characters, while the prompt of higher-level readers was more concentrated on theme. At the same time, readers below grade level were answering "why", "how" and "what if" questions.

To varying degrees, Google Classroom was utilized to engage students in practicing and improving their writing. In Mrs. Welsh's classroom, writing time was differentiated in that different students were pushed according to their ability. For students that were English Language Learners or those that were on an Individualized Education Plans, whether they were working on the same prompt or a more individualized prompt, were given varying goals that may or may not have been congruent with the majority of the class. Thus, during all writing time, the teacher was actively differentiating writing assignments and Google Classroom was a tool utilized to streamline this process.

In addition to the uses of Google Classroom that were recorded, there were also supplemental, group activities in which Google Classroom was employed. However, because instructors other than Mrs. Welsh led these lessons these utilizations were not accounted for. In these activities led by other instructors, Google Classroom technology was not utilized with differentiation aims at the forefront. Thus in my capacity as the student teacher conducting one 
of these lessons it was my underlying pedagogy that was determining the functionality of the technology. For example, in a lesson about museums that I planned and executed in my role as a practicum student, I utilized Google Classroom as a means for groups to create informative, imaginative articles about a topic of their choice. This demonstrates that optimal technology usage of a site like Google Classroom is not universal and is rather determined by the pedagogical views of the teacher.

\section{Seesaw as a Portfolio Tool}

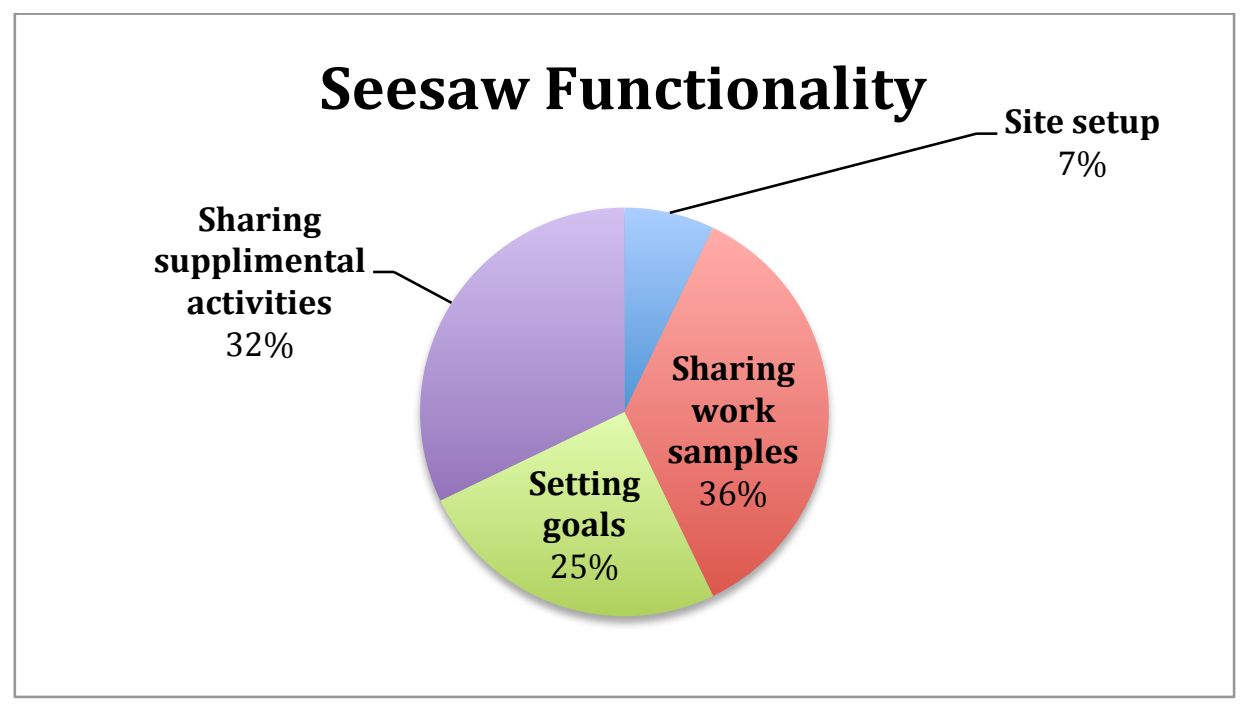

Figure 8. Seesaw functionality

While Google Classroom aims to connect students and teachers in and outside of school, Seesaw takes this a step further by also connecting parents to this conversation. According to the Seesaw webpage, Seesaw has the functionality of creating "digital portfolios for any classroom" ("Seesaw: Features," n.d.). According to the Seesaw site, access to the site is $\$ 120$ per teacher, per year for the fully functioning Seesaw plus account - a cost absorbed by the district. However, it is also stated that if an entire school or district wishes to purchase access, a quote can be requested (Seesaw: Pricing). Also according to the Seesaw Features page, teachers can utilize the 
site to capture student work in many forms including written text, drawing, taking photographs, recording videos and completing voice recordings.

This site also explains that students and teachers can log on and post with ease to Seesaw. This was consistent with the findings of this study because students were able to log on using their Google account information from their Chromebooks. From here, the controls seemed very intuitive, as all functions are accessed through clicking an icon that correlated to the function (for example, to record a video, the student would click an icon that looked like a video camera).

In an interview, Mrs. Welsh shared that she had previously received the message from the school district and other teachers that Seesaw and Google Classroom have similar functionality, thus one must be chosen over the other. However, at the start of the year she went to a training where she spoke to another teacher and learned that that Seesaw and Google Classroom are complimentary, not redundant. When reflecting on her use of both sites in an interview, Mrs. Welsh stated "I use Seesaw for portfolios and Google Classroom for logistics, getting assignments out and grading."

Overall, Seesaw was the site utilized most frequently in Mrs. Welsh's classroom during the study duration at twenty-two out of twenty-six days of the study duration. However, unlike the other sites utilized, Seesaw was occasionally used for different purposes multiple times in the same day. For this reason, Seesaw was utilized twenty-eight times total during the study duration. All of the times that Seesaw was observed being utilized were with the intention of improving student, parent and teacher communication. See Figure 8 for an illustration of the functionality of Seesaw in Mrs. Welsh's classroom.

Two of the Seesaw utilization's ( $7 \%$ ) was for site setup. One of these occasions occurred when Mrs. Welsh did not receive the information that the school had already created 
Seesaw accounts for each student. Thus she attempted to help each student set up an account. The following day Mrs. Welsh received word that the school had already created the accounts. As a result, the subsequent day that I was in the classroom, Mrs. Welsh secured the students' passwords and they all logged on to ensure that all of the passwords successfully logged students onto the site and connected them to the correct class.

Of the twenty-eight observed utilizations of Seesaw, ten utilizations $(\sim 36 \%)$ had the intention of sharing work samples. For example, Mrs. Welsh asked students to write down the most difficult multiplication problem that they felt comfortable solving-- (either one digit by one digit, one digit by two digit, or two digit by two digit). Students then used the drawing function to write out their work on Seesaw. Next, using Seesaw's voice recording function, students orally explained their work. This was posted on Seesaw for the student, parents/guardians and teacher to look back on in order to understand the student's current understanding and make learning goals. Thus, Seesaw became a useful tool in making decisions regarding differentiation. With this information, a group of students expressed holding a similar misconception regarding two-digit by two-digit multiplication problems. While other students worked on Khan Academy/DreamBox, Mrs. Welsh could pull this group to work through this misconception. In addition, parents/guardians could become aware of this misconception and also address it from home.

Seven utilizations of Seesaw (25\%) occurred in order for students to set goals. Mrs. Welsh shared that, in years before Chromebook technology was present, she still had students create goals and share these with parents/guardians. However, she noticed that, without the goal being accessible, students would quickly forget the goal after it was set. Mrs. Welsh stated in this 
interview, "I have always set the goals, but Seesaw reminds them of their goals and they are working towards them, not forgetting them three weeks later.”

To set math goals, students added comments on their tests of a learning target that they wanted to improve as their goal. For reading, the teacher posted a photograph of the students' IRLA card containing specific goals to move up to the next IRLA level. Students then posted the individual aspects that they needed the most work on. For writing, students looked at work samples they posted, such as photographs of their literature response journals from their book groups, to set writing goals. For speech, students recorded themselves giving a speech explaining least five important things about them. After watching this over, students set goals such as speaking louder, reading off of their notecards less or speaking clearly. Behavior goals were less based on work samples posted on Seesaw. If student work exhibited difficulty with work completion this would be set as the goal of that student while the other students were given more choice over behavior goals.

Mrs. Welsh's employment of the goal setting process was central to achieving a differentiated classroom. These goals enabled each student to reflect upon his/her current level, set a goal and create a plan to achieve this goal. Through including the student, the teacher and parent/guardians, everyone gained awareness of the student's individual needs. Thus, each student's learning plan became differentiated through the process of goal creation.

While the aforementioned utilizations of Seesaw were highly individualized, nine of the twenty-eight utilizations of Seesaw $(\sim 32 \%)$ had the purpose of sharing supplemental, classroom community building exercises. For example, photographs of students during art literacy lessons with their art projects or photographs from a field trip to the food bank were posted. In an interview, Mrs. Welsh shared that her belief that building a strong, classroom community is 
central to creating classrooms that are beneficial to all students. As a result, while these posts did hold great merit in connecting the teachers, the student and parents/guardians, the sharing of these activities through Seesaw did not have differentiation as an aim.

As part of this case study, I observed parent-teacher conferences. It is important to note that, because this case study was conducted at a Title I school, students and siblings were encouraged to attend conferences. During an interview, Mrs. Welsh reflected upon the process of having parents already aware of their student's progress prior to fall conferences as a result of Seesaw.

During conferences, I would bring up a goal and the parent would be like 'Yeah, we know we need to work on that' or 'Yes we have talked about that'. And, I'm thinking, wow-these parents and kids are really communicating. And, we get to the last one of the evenings and I talk about using flashcards for math. I gave her [the parent] some and she said 'oh good! We were going to stop on our way home and buy some. This saves us a trip.

I was like 'Wow, it's great that you know that.'

And she looked at me and she goes 'Well... you have it all on Seesaw.' So all of the kids' goals were all up there and they [parents/guardians] already knew what the kids were working on. So, I mean, from that point of view there weren't any surprises. And it's just a good relationship builder to have parents absolutely loving getting to see pictures of their kids everyday.

As reflected in this interview excerpt, Mrs. Welsh noticed that parents/guardians seemed to be keenly aware of their child's specific goals due to viewing these goals on Seesaw. Parents also felt connected with the day-to-day classroom activities, so time did not have to be taken out of the twenty-minute conference to talk this through either. This enabled conferences to be more about operationalizing achieving goals as a parent/guardian, student and teacher team, rather than setting these goals. Overall, Seesaw had functionality in connecting the teacher, the student and parents/guardians through the process of sharing student work samples and individual goals.

Thus, all parties became aware of the individual student's needs in order to differentiate each student's learning outcomes. 


\section{Chromebook Limitations}

Overall, Chromebooks were integral in Mrs. Welsh's day-to-day teaching practice. However, because this research aims to paint an accurate portrait of the way that $1: 1$ Chromebook technology is being utilized in a real classroom, noting the device's limitations becomes crucial.

In observing Chromebook use, the primary limitation of the devices was the student's ability to become easily off task and utilize his/her device for purposes other than the task at hand. For example, because each student was assigned a particular Chromebook, students desired to spend time customizing their device. This meant that, while students were instructed to utilize math time to work on Khan Academy or DreamBox, the student might have a second window open in which they are searching his/her favorite YouTube star in order to download an image for the background of his/her Chromebook.

During an interview, Mrs. Welsh shared expressed that the school district has the intention of integrating "Chromecast" - a device that will enable the teacher to view each student's screen, as they are seeing it, from his/her personal laptop or tablet. Thus, the teacher will be able to more easily ensure that students are on task. However, this is still currently a limitation of the Chromebook over more standard technological tools.

Another limitation to 1:1 integration observed from this case study was that it came with the assumption that students would continue using the sites utilized in class at home. This comes with the underlying assumption that all students have access to both a device and Internet. When asked about this in an interview, Mrs. Welsh stated:

I do know of three or four students that do not have any access in my class. The other students, a lot of them, if they have older siblings in middle or high school, they use the Chromebook of the older sibling and a lot of parents have worked Internet out because the Chromebooks goes back 
and forth between school and home. So, I do have a few students that are using their old siblings Chromebooks because their family has Internet, but they don't have the devices.

This case study was conduced in a Title I school in which $50 \%$ of the student's families were recognized as economically disadvantaged. As a result, the school did not assign pen and paper homework. If parents/guardians wished for their student to have supplementary homework, they were pointed toward the same sites that were utilized in the classroom. Thus, for students without access, completing supplementary homework was not possible, unless supplementary paper homework was requested from the teacher by parent/guardians — which I did not observe occurring.

To combat this issue, the district offered reduced cost Internet access for families that could use this service. Mrs. Welsh shared with me that there is a handout that goes out about this program at the start of every year. However, with the diverse population served by the school, I wonder if this handout went out in languages other than English. Also, half of the battle is helping families gain Internet access, but the other half of the battle comes from not having the devices at home. Therefore, for students that do not have older siblings that can take home their Chromebooks, it seems that there will have to be a device check-out procedure before elementary students can be required to complete homework that requires Internet capabilities.

A final observed limitation was that students that received push-out intervention (English Language Learners, Counseling, Resource Intervention ect.) were not always present when differentiated Chromebook instruction was occurring. Thus, these students that could have greatly benefited from smaller group instruction while other students worked on a lesson on their Chromebooks, were not present in the classroom. Thus, when the students came back into the classroom after their push-out intervention in the middle of the lesson, it was often just asked 
that they read or log onto Khan Academy/DreamBox. In an interview Mrs. Welsh shared that, to her knowledge, technology in these push-out interventions is not often utilized.

While overall Chromebooks were useful in achieving Mrs. Welsh's aim of differentiation, there are other factors at play preventing all students from receiving the full differentiation capacity of Chromebook technology, both school in and at home.

\section{Discussion}

As stated previously, the intention of this research is not to make evaluative assertions regarding technology integration. Rather, the aim of this research is to assist current and future teachers in reflecting upon their own pedagogical lens to make decisions regarding technology implementation. This article aims to provide an example of one teacher's process in working toward this aim, through describing her technology use in tandem with her views on the function of education.

For today's teachers existing in the post-NCLB educational climate, technology is becoming another tool utilized by teachers to achieve the goals that they have for their students that are deeply influenced by their personal, pedagogical beliefs. For Mrs. Welsh this was a lens of differentiation. Through the statements of pedagogical intent made during the interviews for this research and observed pedagogical approach, Mrs. Welsh continuously created and maintained individualized, student goals and assigned work accordingly. On the Chromebooks, Khan Academy/DreamBox, Book Shelf, Google Classroom and Seesaw were utilized in order to bring this pedagogical theory into teaching practice in Mrs. Welsh's classroom.

The differentiation aims made possible by the functionality of Khan Academy and DreamBox was multi-layered in Mrs. Welsh's classroom. On one level, the technology itself 
scaffolds based on student performance. When the assignment was given for students to work on either Khan Academy or DreamBox, the teacher knew that each student had an assignment, tied to common core standards and the current topic, to work on. Due to the different teaching styles of the two sites, they worked symbiotically to differentiate math instruction in Mrs. Welsh's classroom.

While not built into daily instruction as Khan Academy/DreamBox were, Bookshelf was utilized by Mrs. Welsh as a means of ensuring that, despite disparity of access to tangible reading materials, all students had access to books not only at their current level, but also to books of varying genres that could help a student propel to the next reading level. Thus, Bookshelf aided Mrs. Welsh in working toward her aim of a differentiated classroom through increasing access to reading material in a school lacking in financial resources.

Google Classroom was utilized by Mrs. Welsh to increase differentiation capacity through streamlining the process of assigning, printing and evaluating student work. Through Mrs. Welsh's usage of Google Classroom within her class, it became apparent that her pedagogical frame led her to utilize the site with differentiated writing aims. When other instructors utilized this site within the classroom, they utilized it according to their own pedagogical value set. For example, as a future teacher, I currently hold a more constructivist pedagogy. Therefore, in a museum lesson that was planned by me, Google Classroom was utilized with more with group centered, open-ended prompts than Mrs. Welsh's differentiated utilization of the site.

Seesaw was employed by Mrs. Welsh to help students take agency in their learning through the creation of work sample sharing and individualized goal creation. Seesaw further 
connected parents/guardians to this conversation to bring differentiation aims from the classroom into the home as well.

During interviews Mrs. Welsh shared that, even without the Chromebook technology, she would have created individualized packets and assignments at different levels. This demonstrates that Mrs. Welsh's pedagogical practice of differentiation has not been transformed by the Chromebook technology, but rather that this technology has become a tool in assisting her to achieve her pedagogical aims.

Present in the post-NCLB discourse holds the assumption that technology is only as beneficial as its' success in improving teaching practices and, in turn, student achievement. Thus, the teacher is given responsibility for successful technology integration in their classrooms. This is also apparent within the SAMR model in which the belief is that technology must be transformative in order to be viewed as successful. This qualitative student of one teacher's experience integrating 1:1 Chromebooks found that she did so in accordance to achieve her pedagogical belief of differentiated education, not simply to make previously inconceivable lessons possible.

\section{Conclusion}

As a future teacher, I am keenly aware that there is an expectation that I enter the teaching force technologically savvy. I understand that what will set me apart from veteran teacher competitors is that, like my future students, I was expected to be computer literate at an early age. Thus, in some respects, it is expected that valuing technology will be embedded in my pedagogical practice, before I have really had the chance to discover my pedagogical beliefs.

The opposite can be said of the twenty-year veteran teacher who has had time to evaluate who he/she is as an educator, without formulating how technology fits into this schema. 
Thus, it is crucial to understand that, for today's educators in the post-NCLB educational climate, pedagogical formation and technological literacy are so deeply embedded within one another that they become inseparable. Thus, aiming to understand how actual teachers have navigated the task of finding balance between their pedagogical frames and technology use is the way of understanding how students will experience technology in the modern classroom.

In Mrs. Welsh's class, her deeply held pedagogical value of differentiating education to aid students in taking agency of their education drives her implementation of 1:1 student to Chromebook technology. This research demonstrates to current and future teachers that, as each teacher approaches the pressure of implementing technology in this post-NCLB educational climate, understanding teachers' pedagogical beliefs is crucial in understanding how teachers integrate technology in today's classrooms.

\section{Future Research}

This account of technology usage in one Title I classroom demonstrates the need for a more qualitative, descriptive approach to educational technology research. Current research places agency on teachers in the process of utilizing technology in order to increase student outcome. It is an underlying paradigm of educational research that projects that receive research funding are those that utilize qualitative, large-scale studies that prove ways that student achievement can be increased. The discourse community is engaged in creating universal frameworks in which to evaluate the teacher's success in this aim. However, this research demonstrates that a teacher's technology usage is as individualized as his/her underlying pedagogical beliefs. As a result, this research aims to inspire future educational technology researchers and theorists to focus further research on understanding the idiosyncrasy of real teachers, real students and real classrooms before aiming to be evaluative. 


\section{References}

Bookshelf: About. (n.d.). Retrieved January 1, 2018, from Bookshelf website:

https:/www.arcbookshelf.com/?schoolpace=true

Cuban, L. (2001). Oversold and Underused: Computers in the Classroom. Cambridge, MA: Harvard University Press.

Demski, J. (2012). The hard(ware) choice. THE Journal: Technological Horizons in Education, 39(9), 28-35.

Ertmer, P. E. (2005). Teacher pedagogical beliefs: The final frontier in our quest for technology integration? Educational Technology Research \& Development, 53(4), 25-39.

Google Classroom FAQ. (n.d.). Retrieved January 1, 2018, from Google website: https://support.google.com/edu/classroom/answer/6025224?hl=en

Hamilton, E. R., Rosenburg, J. M., \& Akcaoglu, M. (2016). The substitution augmentation modification redefinition (SAMR) model: a critical review and suggestions for its use. TechTrends: Linking Research \& Practice to Improve Learning, 60(5), 433-441.

Harris, J. L., Al-Bataineh, M. T., \& Al-Bataineh, A. (2016). One to one technology and its effect on student academic achievement and motivation. Contemporary Educational Technology, 7(4), 368-381.

How Khan Academy works. (n.d.). Retrieved January 1, 2018, from Khan Academy website: https://www.khanacademy.org/teachers

Kent, T. W., \& McNergney, R. F. (1999). Will Technology Really Change Education? Thousand Oaks, CA: Corwin Press, Inc.

Koehler, M. J. \& Mishra, P. (2013). What is technological pedagogical content knowledge (TPACK)? Journal of Education, 193(3), 13-19. 
Puentedura, R. P. (2016, July 12). The SAMR model: Technological integration Into higher education [Web log post]. Retrieved from Hippasus: http://hippasus.com/rrpweblog/archives/2016/07/SAMRModel_TechnologicalIntegration IntoHigherEducation.pdf

Sahin, A., Top, N., \& Delen, E. (2016). Teachers' first-year experience with Chromebook laptops and their attitudes towards technology integration. Technology, knowledge and learning, 21(3), 361-378.

School and district report card 2016-2017. (2017). Retrieved from Oregon Department of Education website: http://www.ode.state.or.us/data/reportcard/reports.aspx

Seesaw: Features. (n.d.). Retrived December 28, 2017, from Seesaw website: https://web.seesaw.me/learn-more/

Seesaw: Pricing. (n.d.). Retrieved December 28, 2017, from Seesaw website: https://web.seesaw.me/pricing/

Schaffhauser, D. (2015). Three reasons Chromebooks are shining in education. THE Journal: Technological Horizons in Education, 42(3), 22-24.

Tomlinson, C. A. (2014). The differentiated classroom: Responding to the needs of all learners (2nd ed.). Alexandria, VA: ASCD.

Why DreamBox? (n.d.). Retrieved January 1, 2018, from DreamBox website: http://www.dreambox.com/why-dreambox

Windschitl, M., \& Sahl, K. (2002). Tracing teachers' use of technology in a laptop computer school: The interplay of teacher beliefs, social dynamics, and institutional culture. American Educational Research Journal, 39(1), 165-205. 